\title{
0 amor de todo mundo, palavras-sementes para mudar o mundo: gramáticas de resistência e práticas terapêuticas de uso social da linguagem por coletivos culturais da periferia em tempos de crise sanitária
} Everyone's love, seed words to change the world: grammars of resistance and therapeutic practices of the social use of language by cultural collectives from the periphery in times of health crisis

Claudiana Nogueira de Alencar ${ }^{1,2}$

\section{RESUMO}

Este artigo focaliza a produção de uma gramática cultural de resistência a partir da análise de práticas linguisticas de coletivos culturais da periferia de Fortaleza, Ceará, vivenciadas nas cartografias do Viva a Palavra, um programa de extensão comunitária e de educação popular comprometido com o enfrentamento da violência por meio da valorização das formas de vida e práticas autogestionadas de arte e cultura das juventudes periféricas. Foram geradas palavras-sementes, em uma pesquisa

1. Professora Associada do Programa de Pós-Graduação em Linguística Aplicada (PosLA) da UECE. Universidade Estadual do Ceará. Fortaleza, Ceará - Brasil. https://orcid. org/0000-0002-2759-2750. E-mail: claudiana.alencar@uece.br.

2. Pesquisadora Bolsista de Produtividade em Pesquisa do CNPq. 
cartográfica, sob a perspectiva da pragmática cultural. Tais palavras e seus temas geradores permitiram a análise de jogos de linguagem, como os círculos de cultura que, embora produzidos de forma remota, funcionam como práticas linguísticas terapêuticas, diante do sofrimento social, agravado pela pandemia de Covid 19. Para esse estudo, foram articulados os conceitos de palavra-mundo de Paulo Freire com os conceitos de jogos de linguagem e terapia da linguagem de Wittgenstein. Também são centrais os trabalhos de Veena Das sobre o sofrimento social e a gramática cultural. A análise mostra os efeitos da violência nas socialidades dos coletivos periféricos e as práticas linguísticas de resistência à violência, na atual crise sanitária mundial.

Palavras-chave: Gramática cultural; terapia da linguagem; periferia; resistência; violência.

\section{ABSTRACT}

This article focuses on the production of a cultural grammar of resistance from the analysis of linguistic practices of collectives in the periphery of Fortaleza, Ceará, experienced in the cartographies of Viva a Palavra, a community outreach and popular education program committed to confrontation of violence through the valorization of the ways of life and self-organized practices of art and culture of peripheral youths. Wordsworld were generated, in a cartographic research, from the perspective of cultural pragmatics. Such words and their generative themes allowed the analysis of language games, such as culture circles which, although produced remotely, function as therapeutic linguistic practices, in the face of social suffering, aggravated by the Covid 19 pandemic. In this study, Paulo Freire's concepts of word-world were articulated with Wittgenstein's concepts of language games and language therapy. Also central are Veena Das'works on social suffering and cultural grammar. The analysis shows the effects of violence on the socialities of peripheral groups and the linguistic practices of resistance to violence in the current global health crisis.

Keywords: Cultural grammar; language therapy; periphery; resistance; violence. 


\section{Introdução}

"Para mudar o mundo, o amor de todo mundo! O amor de todo mundo para mudar o mundo!" Os versos do poeta Ítalo Rovere ecoavam no palco aberto do Templo da Poesia, espaço cultural ocupado por poetas de Fortaleza, que além de promover a democratização da cultura por meio de saraus levava poemas para os ônibus, realizando intervenções poéticas, dentro dos coletivos e nos terminais de transporte.

O poema tema do Espaço Arte Templo da Poesia "O Amor de todo mundo para mudar o mundo" permite o anúncio da arte comprometida com a transformação das injustiças e crueldades impostas pelo sistema-mundo capitalista excludente e opressor. Um anúncio que se multiplica do palco aberto do Templo da Poesia para os microfones abertos nos saraus da periferia de Fortaleza e que remete à "Pedagogia da Indignação" de Paulo Freire (2000), quando em sua segunda carta pedagógica intitulada "Do direito e do dever de mudar o mundo" nos diz: "É certo que mulheres e homens podem mudar o mundo para melhor, para fazê- lo menos injusto, mas a partir da realidade concreta a que 'chegam' em sua geração" (Freire, 2000, p. 26).

A poesia, a arte e a cultura vivenciadas nos saraus espalhados pela periferia de Fortaleza têm os pés nessa realidade concreta e enunciam esse desejo pela transformação de um contexto preocupante: a violência contra a juventude pobre e negra das periferias das grandes cidades. No Mapa da Violência, o documento intitulado "A Cor dos Homicídios no Brasil”" (Waiselfisz, 2012) já apontava para esse caráter seletivo da violência urbana e estrutural, que exclui socialmente e mata, preferencialmente, jovens negros das classes populares. Para fortalecer as práticas culturais da periferia e ao mesmo tempo lutar contra o extermínio da juventude, artistas, ativistas, acadêmicos e militantes de movimentos sociais e coletivos culturais se reuniram, em 2014, no bairro da Serrinha e constituíram o coletivo Viva a Palavra. Essa articulação permitiu a construção colaborativa de um programa de extensão intitulado "Viva a palavra: circuito de linguagens, paz e resistência da juventude negra da periferia de Fortaleza" (Alencar, 2014).

O programa, que foi registrado na Universidade Estadual do Ceará por mim, demandou diversas ações populares e acadêmicas e tem pro- 
vocado a universidade para reconhecer os saberes e a arte produzidos pelos coletivos culturais e movimentos sociais da periferia, trazendo a produção poética periférica para os seus currículos, realizando aulas, eventos e ações nos bairros periféricos (Alencar, 2014).

Este artigo, situado no âmbito de uma Linguística Aplicada crítica, que chama a atenção para a importância de desenvolvermos pesquisas que apresentem relevância social (Rajagopalan, 2019) e que produzam conhecimentos para combater o sofrimento humano (Moita Lopes, 2006), discute as práticas de arte e de cultura das juventudes nas periferias como práticas de linguagem que buscam enfrentar violências e desigualdades sociais na construção de um "inédito viável" (Freire, 1997). O artigo também pretende discutir a possibilidade de considerarmos essas práticas de linguagem como práticas terapêuticas de uso social da linguagem (Wittgenstein, 1999), e como parte de uma pedagogia da(o)s oprimida(o)s (Freire, 1987), articulando uma visão de linguagem em Paulo Freire com a filosofia da Linguagem ordinária de L. Wittgenstein para pensar a pragmática cultural. Essa perspectiva pragmática também se alimenta do pensamento antropológico, a partir dos trabalhos etnográficos de Veena Das (2007) sobre o cotidiano de mulheres que vivenciaram experiências de violência. É a partir da articulação teórica entre Veena Das, Paulo Freire e Wittgenstein que desenvolvo a ideia de gramática cultural de resistência.

\section{Pragmática cultural e as práticas terapêuticas de linguagem}

O filósofo L. Wittgenstein contribuiu decisivamente para a virada linguística na filosofia ao voltar-se para o modo como a linguagem está imbricada com o mundo. Na primeira fase do seu pensamento, a linguagem era vista como uma figuração da realidade, o que conduziria ao estabelecer de limites para a linguagem, a partir dessa relação de representação expressa no aforismo 5.6: "Os limites de minha linguagem significam os limites de meu mundo" (Wittgenstein, 2008, p.245).

Wittgenstein, contudo, não apenas abandona essa visão representacionista da linguagem, mas passa a criticá-la, quando se volta para a linguagem ordinária, e percebe que não há uma essência para a 
linguagem ou o exercício de função única da linguagem, a de representar o mundo. Ao voltarmos para a vida, o que temos é uma série de atividades que constituem jogos de linguagem.

Em suas Investigações Filosóficas (IF, § 19), obra publicada depois de sua morte, a linguagem passa a ser considerada por Wittgenstein como uma forma de vida (Wittgenstein, 1999, p. 32). O filósofo nos faz olhar para a vida, para as práticas linguísticas, mostrando que é somente na prática, no uso da linguagem, que os significados são constituídos, ou seja, na vida. Para ele (IF, § 432) “Todo signo sozinho parece morto. O que lhe dá vida? - No uso, ele vive" (Wittgenstein, 1999, p. 129). E é a historicidade desse uso que constitui o ordenamento social e uma provisória estabilidade dos sentidos da linguagem, que funcionam como roteiros ocultos a nossas práticas linguísticas e culturais.

Veena Das (1999) chama a atenção para o fato de que formas de vida trazem a "forma" e a "vida". A antropóloga, estudando a violência e a produção de subjetividade feminina, tece uma reflexão sobre a linguagem como forma de vida, a partir do olhar para a inscrição da violência no cotidiano das mulheres que sofreram experiências violentas, em momentos políticos da história da Índia. A possibilidade ou impossibilidade de narrar a violência extrema sofrida, como estupros de mulheres como punição de guerra, está ligada ao que pode ser considerado uma forma de vida. Há um tecido próprio em cada forma de vida que funciona como um roteiro social oculto, uma gramática cultural. Tal gramática diz respeito ao modo como o cotidiano permite a inscrição do que pode ser dito e do que pode ser mostrado, ligando vidas humanas e não humanas, em uma teia de relações que nos fazem constituir sentidos.

Como nos mostra Veena Das (2007), somente o olhar para o cotidiano nos permite perceber como a violência pode ser reinscrita, ressignificada a partir de determinadas formas de vida. Essa criação pela reinscrição da dor no cotidiano nos interessa para perceber como as juventudes da periferia reinscrevem as situações de dor e violência em suas práticas de arte e cultura. Essa inventividade no cotidiano é uma forma de resistência. Como nos diz Deleuze (2011), resistir é criar.

O pensador brasileiro Paulo Freire $(1987,1996,1997)$ também nos mostra que as palavras brotam do nosso cotidiano, como força 
criadora. As palavras-mundo funcionam como palavras geradoras, palavras-sementes que conduzem temas, motivadores de ações político-culturais. Em sua "Pedagogia da Indignação", Freire nos convoca para "experimentar com intensidade a dialética entre a "leitura do mundo' e a 'leitura da palavra' (Freire, 2000, p. 39)". E na "Pedagogia da Esperança", ele nos diz: "nem a leitura apenas da palavra, nem a leitura somente do mundo, mas duas dialeticamente solidárias" (Freire, 1997, p.54).

A partir do pensamento freireano, pode-se também pensar as práticas de linguagem como formas de resistência. Na obra "Educação como Prática da Liberdade" Paulo Freire (1967) nos apresenta as aprendizagens da linguagem como inventividade. Para ele, o aprendizado da leitura e da escrita é visto como ato de criação. Freire (1967, p 104) nos mostra que nesses processos de aprendizado da linguagem ocorrem os estados de procura, de invenção e de reivindicação. Temos aqui uma perspectiva que permite a compreensão da palavra que explode com inventividade no cotidiano.

A Pragmática cultural entende esse fluxo como um encontro. Ela estuda a linguagem como forma de vida, que é sempre coletiva e o faz de modo coletivo. Nessa perspectiva, a Pragmática cultural defende uma pesquisa colaborativa, compreendendo a linguagem como ação-reflexão-ação, como prática ética-estética-social. Seria, portanto, um modo de pesquisa participante que focaliza a construção coletiva do cotidiano. A pragmática cultural, que alia afeto e vida à pesquisa crítica na linguagem, permite a articulação teórica da autora e dos autores aqui já discutidos, Veena Das, Paulo Freire e Wittgenstein para pensarmos as práticas terapêuticas ${ }^{3}$ por meio de uma pesquisa participante nos estudos críticos da linguagem.

Wittgenstein (1999) tem se referido à busca pelo significado como essência e representação como uma doença filosófica. Os filósofos, tais quais moscas que, presas em uma garrafa batem incessantemente contra

3. Wittgenstein (1999) em suas Investigações Filosóficas utiliza o termo terapia a partir da ideia de que os jogos de linguagem podem funcionar como práticas terapêuticas no enfrentamento de uma "doença filosófica" que nos prende a uma visão essencialista da linguagem. No decorrer do artigo, discutirei o modo como essa ideia de práticas terapêuticas podem atuar nas práticas de linguagem da periferia em seu enfrentamento às diversas formas de violência. 
o vidro da garrafa para tentar escapar, gastam seus esforços na busca de exatidão, na busca por significados como entidades abstratas. Para isso abstraem a linguagem das formas de vida e buscam generalizações para encontrar definições exatas para as suas categorias de estudo. Cito o parágrafo das Investigações Filosóficas (IF, § 88): “Ora, 'inexato' não significa 'inútil'. (...) 'Inexato' é propriamente uma repreensão e ‘exato’ um elogio” (Wittgenstein, 1999, p. 60).

Wittgenstein, no entanto, se contrapõe a esse desejo por exatidão. Segundo ele, não há nenhum elemento essencial que permita definir um jogo de linguagem (IF§ 65): o que encontramos entre um jogo ou outro são semelhanças de família (Wittgenstein, 1999, p. 52). Essa imprecisão, vaguidade, que desestabiliza e, ao mesmo tempo, estabiliza os signos em semelhanças de família, é constitutiva da própria gramática. Se há regras que coordenam os jogos de linguagem essas regras não são fechadas, pois são frutos da história cotidiana desses jogos de linguagem. As regras, que constituem a gramática das formas de vida, são culturais, isto é, são inventadas e reinventadas no cotidiano, sendo, portanto, dinâmicas. E é justamente o voltar-se para a vida, o jogar o jogo comum da linguagem ordinária que Wittgenstein apresenta como o terapêutico da linguagem e/ou da vida. Imbricar-se nas formas de vida, nas práticas de linguagem ordinária seria um modo de vencer a doença filosófica representacionista.

A partir de pesquisas etnográficas realizadas com mulheres que sofreram violência, Veena Das (2007) também compreende o trabalho sobre a linguagem cotidiana como um caminho para reinscrever a continuidade da vida, quando os eventos violentos constituem uma gramática da dor que torna o trauma inenarrável. É na vida cotidiana que novos tecidos de significação podem ser costurados para que, na forma de vida de uma coletividade, a dor possa ser dita de outra forma, mostrada em outros jogos de linguagem a partir da gramática cultural de suas companheiras e companheiros.

Nesse mesmo viés, ao pensar um trabalho sobre práticas linguísticas cotidianas como um caminho de superação do sofrimento, Paulo Freire (1996), em "Pedagogia da Autonomia" nos apresenta a necessidade de corporeificação das palavras em nossas práticas. Em "Pedagogia do oprimido" (1987), é o concreto da vida que fornece a 
matéria para as palavras geradoras que se tornam "significações constituídas ou reconstituídas em comportamentos seus, que configuram situações existenciais ou, dentro delas, se configuram para promover: reflexo, reflexão e abertura de possibilidades concretas de ultrapassagem" (Fiori, 1987, p. 7). Ainda segundo Fiori, durante os círculos de cultura propostos por Paulo Freire, na volta à linguagem comum dos sujeitos, para a escolha de palavras que fazem parte do seu cotidiano, as palavras geradoras, a experiência torna-se em "reflexão de si mesma e crítica animadora de novos projetos existenciais" (Fiori, 1987, p. 7).

Desse modo, posso dizer que os Círculos de Cultura são tecnologias sociais, propostas por Paulo Freire para possibilitar não apenas o aprendizado da leitura e da escrita, ou seja, a alfabetização e o acesso ao mundo letrado, mas também a transformação de realidades injustas que conduzem a terapia da linguagem por meio de transformações no ato de retomada do cotidiano para o encontro com o outro e consigo mesmo.

Nesse sentido, trago as palavras geradoras como dispositivos das práticas terapêuticas da linguagem. São as palavras geradoras que como palavras -sementes nos conduzem aos temas geradores, a partir das realidades mesmas dos participantes das interações linguísticas; temas que nos permitem alcançar as gramáticas culturais e pela criação das palavras retomar as experiências de sofrimento social para reinscrevê-las em uma gramática de resistência.

\section{Cartografias juvenis da periferia em tempos de pandemia}

A violência urbana como um fenômeno complexo nos solicita uma compreensão conjunta das relações entre economia, política, produção do espaço urbano e produção de práticas de linguagem. No que diz respeito à essa vulnerabilidade, os movimentos sociais e coletivos culturais da periferia de Fortaleza denunciam um verdadeiro genocídio da juventude pobre, negra e periférica ${ }^{4}$. Sabemos que esse

4. Conforme o Relatório do Comitê Cearense pela prevenção de Homicídios na Adolescência (2016, p.5), em 2015, 816 meninos e meninas de 10 a 19 anos foram mortos no território cearense, sendo 387 apenas na capital Fortaleza". As pesquisas indicam que o 
genocídio é consequência de um necropoder, uma das forças estruturantes do capitalismo neoliberal, que instrumentaliza a vida e detém o poder de morte, gerenciando a destruição de corpos de determinados grupos e populações. Segundo Mbembe (2018) essa política da morte opera como uma macroestrutura em países que sentem os efeitos da colonização. Nesse sentido, em meio às formas de colonialidade que continuam estabelecendo relações cruéis por meio da hierarquização racial, resultantes do sistema capitalista colonial-racista-patriarcal, a necropolítica opera com o seu poder de gerenciar a morte.

Essa política de morte foi agudizada com a crise sanitária de Covid 19. Governos neoliberais primaram por defender o lucro, antes da defesa da vida (Yazbek, 2020). A violência da pandemia também nos fez enxergar o desfinanciamento da saúde e a consequente precariedade dos sistemas para atender a demanda da população adoecida. A ausência de políticas de segurança social e de investimento em áreas sociais, próprias do neoliberalismo, permitiu que as populações que já experimentaram a vulnerabilidade, pela falta de moradia digna, de alimentação suficiente e de condições de saneamento básico, fossem as mais atingidas pela pandemia.

De acordo com Virgínia Fontes (2020), a crise sanitária provocada pela Pandemia de Covid, iniciada em 2020, evidencia a crise capitalista que já estava em curso: a generalizada uberização, a expropriação de direitos da classe trabalhadora e a doação de bilhões dos governos para os capitalistas já eram os sinais dessa crise, conforme aponta Fontes. Segundo ela:

Antes de falar da crise sanitária, é preciso lembrar que já estávamos ingressando numa nova crise capitalista, de novo por superprodução de capitais, pois o enorme volume de capitais, sob forma de títulos ou de dinheiro, que precisam se valorizar, já estavam implodindo a vida social. Longe da falaciosa versão de que "vínhamos crescendo e o vírus pode atrapalhar", apresentada por Trump e por Bolsonaro, a crise já estava em curso, e era anunciada pelos próprios economistas burgueses (Fontes, 2020, p. 2).

Ceará é o estado brasileiro onde mais se matam adolescentes entre 12 e 18 anos. Fortaleza é a capital mais letal para os adolescentes, com IHA (Índice de Homicídios de Adolescentes) de 10,94 mortos a cada grupo de mil jovens (BARROS et al, 2016.). 
Diante do quadro devastador do extermínio da população juvenil periférica, passei a realizar pesquisas como modos de ação, pesquisa cartográfica e pesquisa participante ${ }^{5}$, que além de investigar sobre o lugar da linguagem na constituição do caráter complexo e seletivo da violência (Silva; Alencar, 2013, Alencar, 2014), promovessem também ações de extensão acadêmica que contribuíssem para ampliar direitos e prevenir a violência que atinge a juventude negra que reside em Fortaleza. Agora mais um desafio se coloca: como construir pesquisa participante em plena crise sanitária que aprofundou as desigualdades sociais, também devido à crise do capital já em curso?

Os trabalhos de pesquisa do Coletivo Viva a Palavra já utilizavam o método cartográfico e a pesquisa participante e colaborativa, advinda da educação popular. Por meio do método de procedimento de pesquisa cartográfica, o Coletivo de Pesquisa Viva a Palavra acompanha os processos e não os produtos resultantes desses. Acompanhar processos demanda da pesquisadora/do pesquisador "manter-se no campo em contato direto com as pessoas e seu território existencial" (Passos et al, 2015, p.56). O método da cartografia compreende também uma vivência etnográfica com registro de práticas em diários de campo, filmagem de grupo focal e gravação de entrevistas. No entanto, para além das vivências etnográficas, a cartografia implica em construir um plano em comum entre pesquisadoras/ pesquisadores e as demais pessoas envolvidas na pesquisa para as vivências de práticas construídas na própria pesquisa. A pesquisa, assim, não se contenta em ser descritiva ou interpretativa, mas se torna também interventiva.

Como um "convite a adotar uma certa maneira de estar no mundo, de habitar um território existencial" e se "deixar conhecer e ser conhecido" (Passos et al, 2015), a cartografia permitiu ao Coletivo Viva a Palavra, no qual atuo como uma das coordenadoras da gestão coletiva, uma relação colaborativa com movimentos e coletivos juvenis.

Os dados gerados em pesquisas cartográficas anteriores, permitiram a construção de uma proposta de pesquisa-intervenção em pragmática cultural (Alencar, 2015, 2019) a partir dos pressupostos da educação popular e dos círculos de cultura freireanos. Iniciei um trabalho de 
investigação das gramáticas culturais, a partir da análise da produção de palavras e temas geradores pelos coletivos culturais da juventude. Percebi que as palavras geradoras escolhidas a partir da vida, do universo vocabular dos participantes, as palavras-mundo de Paulo Freire, que chamamos de palavras-sementes por provocarem uma multiplicidade de sentidos em temas geradores, funcionam como pistas para acessarmos as gramáticas culturais dos coletivos juvenis periféricos. Essas palavras-geradoras são caminhos para descrever os jogos de linguagem, e consequentemente, para refletir sobre a problemática da violência urbana, a partir da participação em movimentos sociais, práticas educativas, práticas de cuidado e práticas culturais da juventude.

Desse modo, em diálogo com as/os participantes do Viva a Palavra, o Coletivo de Pesquisa, formado por nós da universidade e pelas pessoas da comunidade, resolveu utilizar a metodologia da educação popular, os círculos de cultura, para compreender a construção das gramáticas de resistência. Com esse coletivo de forças, entendi que o pensar de Paulo Freire sobre linguagem e sobre a vida contribui muito para essa pragmática cultural que aprendemos a construir coletivamente.

Alguém poderia objetar que esse método freireano foi pensado para uma situação específica, para a alfabetização de adultos. Ao que responderei com o enunciar do educador popular, Carlos Rodrigues Brandão (1981, p. 3): "ali não se experimentava só um novo método, mas, através dele, um novo sentimento de mundo, uma nova esperança" no ser humano. Então sigo apresentando essas linhas tecidas pelos becos e ruelas da periferia.

Na primeira etapa de nossa cartografia, realizamos o que Paulo Freire, em Pedagogia do Oprimido, chamou de "investigação do universo temático". Trata-se pois da " descoberta coletiva da vida através da fala, do mundo através da palavra” (Brandão, 1981, p.15). Nessa etapa, escolhemos as palavras-mundo, as palavras-sementes selecionadas a partir dos enunciados das pessoas.

Na segunda etapa, temos a escolha dos temas geradores. Como nos mostra Brandão: cada palavra tem também a sua "carga pragmática que, vimos, é uma combinação de teor afetivo com peso crítico (...) Cada palavra esconde muitas falas porque está carregada dos sinais da dor, luta e esperança" (Brandão, 1981, p.15). Nessa etapa, é preciso 
estar atento aos temas da comunidade: esses assuntos relacionam-se diretamente com as suas formas de vida. Na terceira etapa, temos o debate, a problematização ou a compreensão da vida.

Desse modo, articulou-se a pesquisa cartográfica com a proposta metodológica dos Círculos de Cultura da Educação Popular. Essa articulação se deu pelo próprio mapeamento do território existencial e do plano em comum entre as/os participantes da pesquisa. A pesquisadora-cartógrafa precisa traçar o seu caminho a partir do modo como o fluxo dos coletivos vai compondo o seu mapa existencial. E esse mapa é sempre aberto. Como afirma Deleuze e Guattari, o mapa é conectável em todas as suas dimensões, "desmontável, reversível de receber modificações constantes". Ele pode ser rasgado, revertido, adaptar-se a montagens de qualquer natureza, ser preparado por um grupo ou uma formação social” (Deleuze; Guattari, 1995, p.22).

Lembro que na cartografia, a pesquisadora-cartógrafa segue processos. Nesse caso, cada deslocamento, cada mudança no fluxo da pesquisa é matéria mesma da investigação. A rota é conduzida pelas/ pelos participantes. Como afirma Gorczevski (2015, p. 191) "na própria constituição do mapa são delineadas as características do território. (...). Há linhas nas pessoas, nas tecnologias, nos aprendizados, na arte'.

Desse modo, quando iniciamos a pesquisa-intervenção em 2015, a primeira etapa metodológica para traçarmos essas primeiras linhas cartográficas foi a "investigação do universo temático", através do conhecimento das intervenções juvenis existentes, conhecendo grupos, coletivos, movimentos e projetos que atuavam na Serrinha. Esse processo de pesquisa-vivência dos círculos de cultura foi analisado por mim anteriormente (Alencar, 2015). As palavras-mundo, palavrassementes enunciadas que se transformaram em temas geradores foram violência, juventudes, cultura e educação popular. Os coletivos de educação popular já atuavam no território da Serrinha, também ligados ao coletivo Ekobé6, promovendo processos formativos em educação

6. O Espaço Ekobé foi constituído por educadores populares como forma de estabelecer diálogos entre os saberes disciplinares da Universidade, aqueles desenvolvidos na prática profissional e os gestados nas experiências de movimentos populares, mantendo-se como extensão comunitária pelo protagonismo dos movimentos populares de saúde de Fortaleza e região metropolitana que mantêm um espaço de cuidados individuais e coletivos. O Ekobé foi delineado na interface da Articulação Nacional de Movimentos e Práticas 
popular com as temáticas das práticas populares de cuidado, da arte, cultura e comunicação popular.

Nesse sentido, no primeiro encontro do Coletivo de Pesquisa para elaborar o projeto do Viva a Palavra estavam presentes os cuidadores e educadores populares do Ekobé, juntamente com o coletivo dos saraus, o movimento hip hop, a associação de moradores e os movimentos sociais. A Educação Popular é uma das linhas de composição do mapa e do território de pesquisa. Desse modo, o Coletivo de Pesquisa Viva Palavra passou a realizar, desde 2015, tanto os Círculos de Cultura quanto os Saraus como um dos traçados metodológicos em sua pesquisa de campo, de viés cartográfico.

Em 2019, uma série de Círculos de Cultura foram realizados na Comunidade Guaribal, na Serrinha, em Fortaleza, como parte das aprendizagens do Viva a Palavra em Educação Popular e Cenopoesia. Os encontros foram animados pela educadora popular, médica e cenopoeta Vera Dantas e pelo artista, educador e cenopoeta, Ray Lima. Durante os finais de semana dos meses de maio e junho de 2019, artistas, ativistas, educadores populares e estudantes participaram desses Círculos de Cultura, Feira do Soma Sempre ${ }^{7}$, corredores de cuidado, cortejo pelas ruas da comunidade, que culminaram em um Ato Cenopoético, elaborado por Ray Lima, como síntese criativa daqueles encontros.

Um desafio que se colocou com a Pandemia de Covid 19 e com a necessidade de isolamento foi como dar continuidade a esses encontros. Assim como fizeram diversos movimentos sociais e coletivos,

de Educação Popular e Saúde (ANEPS), a Universidade Estadual do Ceará (UECE), a Secretaria Municipal de Saúde de Fortaleza e o Ministério da Saúde e estruturado durante a 57 Reunião Anual da Sociedade Brasileira para o Progresso da Ciência (SBPC) em 2005.

7. Segundo Ray Lima (2009) a Feira do Soma Sempre seria "uma simulação de rede social, de como os sujeitos em rede interagem, se relacionam e ou podem se relacionar numa comunidade ou movimento social com vistas a uma sociedade democrática, cuidadora e solidária." Ray Lima propõe como dinâmica e regra do jogo: "definição de pequenos grupos por experiência e organização de espaços específicos para que cada um conte sua história (experiência) aos demais que estarão circulando em busca da novidade do outro, o que é, como se deu caminhada, o que tem feito, como arma suas estratégias de existência e resistência, etc". Lima, Ray. Feira do Soma Sempre e a Produção do Comum. Blog Rede Humaniza Sus, Rio de Janeiro, 10 agosto de 2009. Disponível em: https:// redehumanizasus.net/7391-feira-do-soma-sempre-e-a-producao-do-comum/. Acesso em: 23.08.2021. 
poderíamos realizar reuniões utilizando plataformas como o Google Meet. No entanto, como realizar de forma remota encontros que exigiam a proximidade, sem as mãos dadas na ciranda, sem o toque no corredor de cuidados, sem os abraços, se a educação popular se realiza por "aprendizagens com o corpo todo" (Dantas; Silva. Castro Junior, 2020)? De qualquer modo, precisávamos nos encontrar para dar continuidade às aprendizagens. Foi então que o Coletivo de Pesquisa resolveu promover, em agosto de 2020, a I Jornada Virtual em Cenopoesia e Educação Popular, pela plataforma do Google Meet. Realizamos duas jornadas virtuais, uma no primeiro semestre e outra no segundo semestre de 2020.

Embora estivéssemos afastadas/afastados presencialmente, pude perceber que esses encontros nos envolviam em cuidado e afeto. $\mathrm{O}$ círculo foi mantido, embora não estivéssemos, na plataforma, em formato de círculo. O círculo era um território existencial. Mesmo na modalidade remota, a corporeidade, o cuidado, a presença da outra era forte, por meio da cenopoesia. O Coletivo de Pesquisa percebeu que o conceito de território deve ser considerado de modo amplo. Os encontros de Cenopoesia, mesmo por meio remoto, faziam com que o Coletivo se sentisse em casa, como nos diz Guattari e Rolnik (1996, p. 236): "o território pode ser tanto relativo a um espaço vivido quanto a um sistema percebido no seio do qual um sujeito se sente "em casa"".

Desse modo, embora o Coletivo Viva a Palavra tivesse sido levado pela crise sanitária imposta pela Covid 19 a promover encontros com interações mediadas por computador, percebi que a amorosidade, o cuidado, a proximidade das pessoas continuava. Como afirmou a pesquisadora Christine Hine (2000), as tecnologias como artefatos culturais conferem uma nova perspectiva para os conceitos de espaço, de temporalidade e, principalmente, sobre o que entendemos como "presença". Antes mesmo do período de isolamento social imposto pela Pandemia de Covid 19, a autora já apresentava os complexos processos de modelagem social que envolvem a internet. Para Hine (2015), as tecnologias são intrinsecamente sociais. Segundo a pesquisadora, "nossas experiências e expectativas sobre as tecnologias são moldadas por processos sociais que colaboram, fazendo essas tecnologias terem sentido para grupos específicos de pessoas" (Campanella, 2015, p, 168). 
O Coletivo Viva a Palavra estava vivenciando a "permeação" de que nos fala Hine (2015), quando grupos que se conhecem por outros meios passam a ocupar as plataformas de interação social, disponibilizadas na internet. Foi assim que, em 2021, para ampliar os encontros com outros coletivos, o Viva a Palavra passou a transmitir os encontros na sala do Google Meet para o canal do Youtube, dialogando com os outros coletivos pelo chat do Canal do Viva a Palavra ${ }^{8}$. Iniciou-se então uma jornada virtual de diálogos entre o Coletivo Viva a Palavra e o Ekobé, que acontece mensalmente no último sábado de cada mês, até o final do ano de 2021.

Por uma questão de delimitação, devido aos limites do artigo, optei por focar a análise em um único encontro da Jornada Diálogos entre Educação Popular e Cenopoesia, intitulado: "Palavra-mundo, Palavra-semente: a experiência comunitária no Viva a Palavra". A escolha se deu porque esse encontro, com a presença de membros da comunidade e da universidade, trouxe o tema discutido neste artigo: as trajetórias cartográficas do Coletivo Viva a Palavra e as práticas culturais da juventude da periferia como parte das redes de resistência à violência urbana.

\section{Palavra-mundo, Palavra-semente: a experiência comunitária no Viva a Palavra}

Viva a palavra! Viva a Palavra! Entoam as/os cenopoetas participantes do Encontro da Jornada Diálogos entre Educação Popular e Cenopoesia, intitulado: "Palavra-mundo, Palavra-semente: a experiência comunitária no Viva a Palavra". O encontro aconteceu na plataforma Google Meet e foi ao mesmo tempo, transmitido pelo Canal do Viva a Palavra na plataforma Youtube ${ }^{9}$. As pessoas animadoras do encontro são participantes de vários projetos do Viva a Palavra. Para apresentá-las, usei os codinomes que elas mesmas escolheram, a partir da ideia de palavras-sementes que fez parte do título do encontro e da autorização de cada uma para fazer parte da pesquisa-intervenção.

8. Disponível em https://www.youtube.com/channel/UCkIwCWYMfiwmaXvwtb94xnA 9. https://www.youtube.com/watch? $\mathrm{v}=$ srJNNgrsaCE. Transmitido em 25 de setembro de 2021 . 
Participante 1: Semente de feijão, cenopoeta e educador popular, participante do Coletivo de Cenopoesia do Viva a Palavra, morador do Siqueira, na Periferia de Fortaleza;

Participante 2: Semente de juazeiro, professora da rede básica de ensino, participante da coordenação coletiva do cursinho popular Viva a Palavra, e moradora da Maraponga, próximo ao Itaperi, campus sede da UECE, na periferia de Fortaleza;

Participante 3: Semente de girassol, artista, participante de vários coletivos culturais, dentre eles o Gás Carbônico e o Sarau Viva a Palavra, morador da Serrinha, na periferia de Fortaleza;

Participante 4: Semente de samambaia, poeta e produtor cultural, participante do Biblioteca Viva a Palavra e do movimento de bibliotecas de iniciativa popular Bibliotecanazaria, morador do Jardim América, próximo ao Centro de Humanidades da UECE;

Participante 5: Semente de algodão, cenopoeta e educadora popular, participante do Coletivo de Elaspoemas: escrita periférica, professora da UECE e moradora do Dionísio Torres, em Fortaleza.

O Coletivo de Pesquisa reunido anteriormente decidiu vivenciar, nesse encontro online, o ato cenopoético que havia acontecido na comunidade Guaribal, em junho de $2019^{10}$. Agora em setembro de 2021, $\mathrm{o}$ ato foi retomado em interação por meio remoto, na internet.

O ato cenopoético iniciou como poema Minha Palavra de Ray Lima, declamado pela participante Semente de algodão:

Palavra-perigo

Palavra-operária

Sente porque vive o cotidiano das coisas

Como a cenopoesia é "a linguagem da arte trabalhada pelo movimento popular", assim nos diz a cenopoeta e educadora popular Vera Dantas (2009, p.5), o Coletivo Viva a Palavra escolheu que seria a cenopoesia que nos daria essa proximidade e os afetos necessários para o diálogo entre diversas práticas artísticas, culturais e práticas de

10. Lima, Ray. Ato Cena Poético Para não seguirmos sonâmbulos ante ao desastre. Mimeo, Fortaleza, 2019. 
cuidados. Segundo a autora, a cenopoesia "nos impulsiona para as possibilidades de diálogo entre as diversas linguagens da arte". É ela que possibilita percebermos a perspectiva da linguagem como açãoreflexão-ação. Como nos diz Nicole Cruz (2018), a Cenopoesia:

se constituiu não apenas em um encontro entre teatro e poesia, mas como um diálogo entre saberes, artes e gentes que jogam no ato o seu repertório cultural humano e assim o acontecimento vai se investindo liricamente de palavras a ações que se juntam umas às outras por amor, e não por sintaxe . (Cruz, 2018, p. 17).

No ato Semente de juazeiro, declama a denúncia: "a globalização é a hegemonia dos valores do norte sobre o sul, é a continuação por meios econômicos, da colonização, que era política". (Lima, 2019, p.7). E Semente de algodão anuncia nos versos de Ray :

Chegou a hora, meu povo, chegou a hora

De coibir assalto à democracia;

Chegou a hora de evitar nova sangria

Na ética, no Brasil que nos implora (Lima, 2019, p.3).

Posso dizer que a cenopoesia é um jogo de linguagem que funciona como uma prática terapêutica da linguagem, uma vez que a criação artística na cenopoesia, a criação do ato cenopoético é a reinvenção, ressignificação de vivências de um coletivo. O roteiro cenopoético é ressignificação de palavras-sementes do universo vocabular dos participantes, pois nasce da "investigação do universo temático" das/dos participantes. Foi a interação dos participantes nas vivências do Viva a Palavra, durante os fins de semana de maio e junho de 2019, que possibilitaram a descoberta coletiva da vida. Cenopoesia é a linguagem ordinária inscrita em poesia por meio das falas das/dos participantes dos coletivos. Naquele encontro online, o ato vivenciado presencialmente, foi revivido, reinscrito em nova forma de proximidade.

Após o ato cenopoético, as/os participantes do encontro no Google Meet, representantes de projetos do Viva a Palavra "entraram na roda" trazendo pequenas narrativas sobre suas trajetórias e projetos do Viva a Palavra. Dessas narrativas, trouxe alguns excertos: 
Excertos - Semente de girassol:

1. Eu venho de alguns movimentos culturais de Fortaleza, e de outros lugares, como o movimento escambo de rua, e de lá a gente fluiu; venho desde o movimento punk (...) Andava por muitos cantos (...). Fiquei a ser mais frequente no bairro e a gente conheceu o movimento hip hop MH2O. Aí acabou um pouco as gangues com a questão do hip hop, com o poder da palavra e aí foi uma transformação assim porque o hip hop me abraçou assim do jeito que eu era.

2. (...) a gente consegue falar em várias linguagens levando sempre a questão social.

3. (...) O cine foi uma coisa assim...muito massa, porque a gente conseguiu entrar nas comunidades, - que era um problema até hoje. Com o cinema, com a arte, a gente conseguiu agregar as crianças, as mães, foi muito bom...

4. (...) Interessante que a gente não criou barreiras, a gente frequentava o Bom Jardim, o Conjunto Esperança, o Pirambu, o famoso Pirambu.

Preciso retomar o trabalho de Veena Das $(1997,2004,2007)$ sobre a dor e o sofrimento social para analisar as cenas narrativas desse encontro. Assim como Wittgenstein (1992a, 1992b) fala de uma gramática da dor para mostrar que não se pode ter uma compreensão da dor fora de jogos de linguagens sempre coletivos, Veena Das defende que o sofrimento deve ser entendido a partir de um complexo social, cultural, econômico e político, que recebe significação no cotidiano.

Nessa perspectiva, o sofrimento deve ser compreendido a partir de uma partilha de sentidos, uma vez que a dor, a violência, o sofrimento só podem ser entendidos ao se considerar a experiência coletiva que se expressa a partir de uma gramática, uma gramática cultural. Nesse sentido, a violência vivenciada nas cidades e que atinge de modo preferencial a população periférica deve ser analisada como uma forma de sofrimento social, que atinge as juventudes. Uma das formas de manifestação dessa violência é o modo como jovens são impedidos de se deslocar de um bairro para outro, ou mesmo de uma rua a outra de sua comunidade. Essas linhas invisíveis traçadas pelas organizações 
criminosas afetam em muito as vidas juvenis. Nos excertos narrativos acima, Semente de girassol se refere a esse sofrimento social, ao falar da impossibilidade de deslocamento imposta pela criminalidade organizada e ao mesmo narra os novos traçados e as "barreiras" quebradas pelo nomadismo dos coletivos culturais juvenis (Alencar, 2019), como se pode ler no trecho do excerto 3: muito massa, porque a gente conseguiu entrar nas comunidades, o que era um problema até hoje. Eno 4: interessante que a gente não criou barreiras, a gente frequentava o Bom Jardim, o Conjunto Esperança, o Pirambu, o famoso Pirambu.

No excerto 1, o participante enuncia um movimento de transformação sobre a situação de violência urbana e seus efeitos sobre as vidas de jovens e das comunidades periféricas: Aí acabou um pouco as gangues com a questão do hip hop, com o poder da palavra e aí foi uma transformação assim porque o hip hop me abraçou assim do jeito que eu era.

Quando Semente de girassol se refere ao "poder da palavra" e ao acolhimento que recebeu, consigo relacionar esse poder à reinscrição do trauma e do sofrimento por meio de práticas cotidianas que ressignificam as experiências de violência. Nas práticas de linguagem da arte e da cultura, o participante encontra uma terapia no uso social da linguagem, nos processos significativos das práticas culturais. Como ele diz no excerto 2 , nessas práticas artísticas de intervenção dos coletivos: a gente consegue falar em várias linguagens levando sempre a questão social.

Na cena narrativa daquele Encontro de Diálogos Cenopoéticos, Semente de feijão responde às falas de Semente de girassol indicando uma palavra-geradora que se transforma no tema gerador deste nosso artigo:

Excertos - Semente de feijão:

5. Eu acho que tem uma coisa nessa tua fala, na tua narrativa resumida de história de vida, que é uma coisa que me chama muita atenção, que é uma coisa, na verdade é uma palavra que, creio eu, que ela é fundamental, e ela não é uma palavra que está na moda, ela não é uma palavra... que 
- pessoal tem a mania de falar que é uma palavra que está na moda, que é uma palavra cansada, que é a palavra "resistência".

6. Eu venho conversando com outra galera, com outros coletivos e artistas aí que a gente está num momento mesmo de assumir a nossa existência, a existência do território.

Parece-me que a fala de Semente de feijão alcança a segunda etapa do círculo de cultura, quando são escolhidos os temas geradores. $\mathrm{O}$ participante seleciona as palavras geradoras "resistência" e "existência" e elabora o tema da comunidade: a resistência relacionando-a diretamente com a existência das juventudes periféricas, suas formas de vida, imbricadas de arte e da cultura, tão cotidianas naquelas comunidades.

Esses temas, que nos conduzem à gramática de resistência da juventude, também são tocados nas narrativas do participante 4 , que escolheu o codinome Semente de samambaia:

Excertos - Semente de samambaia:

7. Essas bibliotecas são muito mais do que bibliotecas, são centros culturais na periferia, centros de cuidado (...)

8. Sábado fiquei sabendo aquela história do seu aluno...É um exemplo bem prático de como o trabalho do Viva a Palavra afasta esse jovem da galera do tráfico, porque se o estado não entra com os seus bens culturais, a única referência que esse meninos vão ter é o cara do tráfico, vão querer ser igual ao cara do tráfico. Se a gente entra na comunidade e tem o próprio pessoal da comunidade realizando atividades de mediação de leitura, realizando atividades de cultura e outras atividades diversas, essa galera vai ser referência pros meninos mais novos.

Nos excertos 7 e 8, "Semente de samambaia" enuncia novos sentidos para cultura: o de cultura como cuidado. Raymond Williams (2007, p.117) estudando os sentidos para a palavra cultura afirma que " em todos os primeiros usos cultura era um substantivo que se referia 
a um processo: o cuidado com algo, basicamente com as colheitas e com os animais".

Quando o participante lembra, no excerto 8, que a cultura pode ser um modo terapêutico de disputar os sonhos da juventude, retoma o sentido de cultura como cuidado, que, no Viva a Palavra, mostra-se como uma prática amorosa e cidadã. Como nos diz Ray Lima em sua cenopoesia: "cuidar do outro é cuidar de mim, cuidar de mim é cuidar do mundo" (Lima, 2013, p. 64).

Desse modo, pode-se dizer que as palavras- sementes, as palavras geradoras nos levam a temas, como os que foram frutos dessa colheita de palavras nos Diálogos online entre Educação Popular e Cenopoesia: arte, paz, transformação social, cultura e cuidado. São esses temas geradores que nos permitem alcançar as gramáticas culturais periféricas e, pela inventividade e terapia de jogos de linguagem, possibilitam retomar as experiências de sofrimento social para re-inscrevê-las em uma gramática de resistência.

Em meio à crise sanitária da Covid 19, o aprofundamento das desigualdades tem mostrado a sua face por meio das políticas de morte promovidas pelo capitalismo neoliberal. De sua constituição também faz parte a disseminação de valores como o individualismo, o egoísmo, o desprezo pela vida humana. Quando os coletivos culturais trazem em suas práticas linguísticas palavras-sementes que enfrentam esses valores prejudiciais à dignidade humana, pode-se perceber que tais palavras são índices de uma gramática cultural de resistência. Reconheço que "arte", "transformação social", "cultura" e "cuidado", as palavras-sementes geradas na pesquisa-intervenção aqui trabalhada, pertencem a uma política de promoção da vida.

Nas periferias das grandes cidades, tenho visto a organização e autogestão por meio da solidariedade das comunidades que realizam ações como prevenção, monitoramento e acompanhamento de pessoas infectadas pelo coronavírus, assistência à população em situação de rua, distribuição de cestas básicas e outras práticas de promoção da vida. Pode-se considerar que, condizente com essas ações, o sarau, as vivências cenopoéticas, os círculos de cultura, promovidos pelo Viva a Palavra, de modo remoto neste período de pandemia, são jogos de linguagem que fazem parte das práticas de cuidado que se contrapõem 
ao individualismo, ao egoísmo, à exclusão social e ao abandono da população vulnerável por parte de governos comprometidos com a necropolítica. As palavras-sementes produzidas nesses jogos de linguagem geram temas constitutivos da gramática de resistência das juventudes do Coletivo Viva a Palavra na periferia de Fortaleza.

Com a análise, espero ter mostrado como os círculos de cultura podem contribuir tanto na geração de dados, nos processos de pesquisa-intervenção, como nos procedimentos de análise em três fases ${ }^{11}: 1$. análise das palavras-semente, as palavras-mundo; análise dos temas geradores para traçar as linhas das formas de vida da comunidade; 3 . discussão dos temas geradores em determinada forma de vida para compreender as gramáticas culturais, a partir dessas formas de vida.

Não posso deixar de afirmar que os jogos de linguagem, como os círculos de cultura e as vivências cenopoéticas, são práticas terapêuticas que permitem a ressignificação do sofrimento social, da violência em novas formas de vida, baseadas no cuidado, na arte e na cultura como transformação social.

\section{Algumas palavras finais}

Neste artigo, busquei refletir sobre o papel da linguagem diante de uma esmagadora realidade: a violência que assustadoramente extermina jovens pobres da periferia, física e simbolicamente. Violência que se acentua com a crise atual do capitalismo e com a crise sanitária pela Pandemia de Covid 19. A discussão aqui realizada intentou contribuir em mais um passo para que a Linguística Aplicada, enquanto produtora de saberes acadêmicos voltados para as práticas sociais, possa se juntar aos esforços de enfrentamento à violência e inclusão social de jovens em territórios atingidos pelos mais altos índices de violência urbana.

Um dos legados do grande educador Paulo Freire, cujo centenário comemoramos neste setembro de 2021, é a ideia de que o domínio da linguagem é um modo de compreender e transformar a realidade em que vivemos. A área de Letras e Linguística está, cada vez mais, 
comprometida em entender a dialética da relação entre linguagem e sociedade e em refletir sobre a contribuição do profissional dessa área para a mudança social.

Nessa direção, o Programa Viva a Palavra que articula ensino, pesquisa e extensão, ao buscar realizar pesquisas e ações acadêmicas voltadas para o fortalecimento da trajetória dos jovens, realiza práticas de linguagem, como as vivências cenopoéticas e os círculos de cultura, que atuam como práticas terapêuticas de uso social da linguagem, contribuindo para a valorização da vida das juventudes das comunidades periféricas, semeando palavras-sementes de esperança, tão necessárias em nosso tempo.

\section{Conflito de interesses}

A autora declara não ter qualquer conflito de interesse, em potencial, neste estudo e assume responsabilidade total pelo conteúdo do artigo.

\section{Contribuição dos autores}

A autora declara que ela mesma realizou a pesquisa e é responsável pelas informações do artigo.

\section{Referências}

Alencar, C. (2019). Tudo aqui é poesia: a pragmática cultural como pesquisa participante com movimentos sociais e coletivos juvenis em territórios de violência urbana. Interdisciplinar, v. 31, p. 237-256. DOI: https://doi.org/10.47250/intrell.v31i1.11848

. (2015). Pragmática cultural: uma proposta de pesquisa- intervenção nos estudos críticos da linguagem. In: Rodrigues, M.G, Abriata, V.L. R., Melo, G.C.V. de, Manzano, L.C.G, Câmara, N. S. (Org.). Discurso: sentidos e ação. Franca: Unifran, v. 10, p. 141-162.

. (2014). Projeto de extensão: Programa Viva a Palavra circuitos de linguagem, paz e resistência da juventude negra na periferia de Fortaleza. Pró-Reitoria de Extensão da Universidade Estadual do Ceará. Fortaleza, 37p.

Barros, J. P. P. et al. (2016). Pacificação nas periferias: discursos sobre as violências e o cotidiano de juventudes em Fortaleza. Revista de Psicologia, Fortaleza,v. 9, p. 117-128. 
Brandão, C.R.(1981). O que é Método Paulo Freire - Volume 38. Coleção Primeiros Passos, São Paulo: Editora Brasiliense.

Campanella B. (2015). Por uma etnografia para a internet: transformações e novos desafios. Matrizes, 9(2), 167-173. DOI: https://doi. org/10.11606/issn.1982-8160.v9i2p167-173

Ceará. (2016). Cada Vida Importa: Relatório final do Comitê Cearense pela Prevenção de Homicídios na Adolescência. Fortaleza.

Cruz, N. N. (2018). Cartas para desver o conceito de resto: a cenopoesia no Hotel da Loucura. Dissertação (Mestrado em Artes Cênicas) Programa de Pós-Graduação em Artes Cênicas, Universidade Federal do Rio Grande do Sul, Porto Alegre. $181 \mathrm{f}$.

Das, V. (1997). Language and body: transactions in the construction of pain. In: Kleinman, A., Das, V., Lock, M. (Ed.). Social suffering, Berkeley: University of California Press.

. (1999). Fronteiras, violência e o trabalho do tempo: alguns temas wittgensteinianos. Rev. bras. Ci. Soc. 14 (40), p. 31-42. DOI: https:// doi.org/10.1590/S0102-69091999000200003

Das, V. et al. (Orgs.). (2004). Violence and subjectivity. Berkeley: University of California Press.

Das, V. (2007). Life and Words: violence and the descent into the ordinary, University of California Press, Berkeley, Los Angeles, London. (Trad. Bras. Bruno Gambarotto. São Paulo, Editora Unifesp, 2020).

Dantas, M. A., Silva, M. R. F., Castro Júnior, A. R. (2020). Aprendizagens com o corpo todo na (trans)formação de educadores (as) populares do Curso Livre de Educação Popular em Saúde (EdPopSUS). Interface (Botucatu. Online), v. 24, p. 1-18. DOI: https://doi.org/10.1590/ Interface. 190205

Dantas, V. L. A. (2009) Dialogismo e arte na gestão em saúde: a perspectiva popular nas cirandas da vida em Fortaleza-CE. Tese (Doutorado em Educação) - Universidade Federal do Ceará, Programa de Pós-graduação em Educação Brasileira, Fortaleza-CE. 323f.

Deleuze, G. (2011). A literatura e a vida. In: Crítica e clínica (pp.11-17). São Paulo: Ed. 34.

Deleuze, G., \& Guattari, F. (1995). Mil Platôs. São Paulo: Editora 34.

Fiori, E. (1987). Aprender a dizer a sua palavra. Prefácio. In: Freire, P. Pedagogia do Oprimido. 17a Edição. Rio de Janeiro: Paz e Terra.

Freire, P. (1967). Educação como Prática da Liberdade. 1a Edição. Rio de Janeiro: Paz e Terra.

(1987). Pedagogia do Oprimido. 17a Edição. Rio de Janeiro: Paz e Terra. 
educativa. 25a edição. São Paulo: Paz e Terra.

. (Org.). (1997). Pedagogia da esperança: um reencontro com a pedagogia do oprimido. 4. ed. São Paulo: Paz e Terra.

. (2000). Pedagogia da Indignação: cartas pedagógicas e outros escritos. São Paulo: Unesp.

Fontes, V. (2020). Coronavírus e a crise do Capital - Entrevista com Virgínia Fontes. In: Site da Associação dos Docentes da Universidade Federal de Sergipe (ADUFS). Disponível em: https://adufs.org.br/ conteudo/1883/coronavirus-e-a-crise-do-capital-entrevista-comvirginia-fontes. Publicada em 16/04/2020. Acesso em 26/08/2021

Guattari, F., Rolnik, S. (1996). Micropolitica: cartografias do desejo. Petrópolis, RJ: Vozes.

Gorczevski, D. (Org.). (2015). Arte que inventa afetos. 1. ed. Fortaleza, Imprensa Universitária - UFC, p. 187-202.

Hine, C. (2000). Virtual Ethnography. London: Sage Publications. . (2015). Ethnography for the internet: embedded, embodied and everyday. Huntingdon, GBR: Bloomsbury Publishing.

Lima, R. (2009). Feira do Soma Sempre e a Produção do Comum. Blog Rede Humaniza Sus, Rio de Janeiro, 10 agosto de 2009. Disponível em: https://redehumanizasus.net/7391-feira-do-soma-sempre-e-aproducao-do-comum/. Acesso em: 23.08.2021.

. (2013). De sonhação a vida é feita, com crença e luta o ser se faz: roteiros para refletir brincando : outras razões possíveis na produção de conhecimento e saúde sob a ótica da educação popular / Ministério da Saúde, Secretaria de Gestão Estratégica e Participativa, Departamento de Apoio à Gestão Participativa. - Brasília: Ministério da Saúde. 252 p.

Lima, R. (2009). Lâminas. Fortaleza: Expressão Gráfica.

Lima, R. (2019). Ato Cenopoético - Para não seguirmos sonâmbulos ante ao desastre. Mimeo, Fortaleza.

Martins, R. L. (2021). Performances de solidão da mulher negra: Insubmissa Negra Voz. [Trabalho de Conclusão de Curso]. Universidade Estadual do Ceará.

Mbembe, A. (2018). Necropolitica . 3. ed. São Paulo: n-1 edições.

Moita Lopes, L. P. (2006). Uma linguística Aplicada mestiça e ideológica: interrogando o campo como linguista aplicado. In: Moita Lopes, L.P. (Org.). Por uma linguística Aplicada Indisciplinar. São Paulo: Parábola.

Passos, E. et al. (Orgs.). (2015). Pistas do método da cartografia: Pesquisaintervenção e produção de subjetividade. Porto Alegre: Sulina. 
Rajagopalan, K. (2019). Uma Linguística Aplicada Plenamente Emancipada: um Sonho ou uma Perspectiva Concreta?. Revista Linguagem em Foco, Fortaleza, v. 2, n. 3, p. 13-18.

Silva, D. N., Alencar, C. N. (2013). A propósito da violência na linguagem. Cadernos de Estudos Linguísticos. Campinas, SP, v. 55, n. 2, p. 129-146, 2013. DOI: 10.20396/cel.v55i2.8637294.

Waiselfisz, J. J. (2012). Mapa da Violência: A Cor dos Homicídios no Brasil. Rio de Janeiro: CEBELA, FLACSO; Brasília: SEPPIR/PR.

Williams, R. (2007). Palavras-chave: um vocabulário de cultura e sociedade. São Paulo: Boitempo.

Wittgenstein, L. (1992a). O livro azul. Lisboa: Edições 70. . (1992b). O livro marrom. Lisboa: Edições 70. . (1999). Investigações Filosóficas. [Tradução José Carlos Bruni] São Paulo: Editora Nova Cultural. (Edição Os Pensadores). . (2008). Tractatus Logico-Philosophicus. Trad. Luis Henrique Lopes dos Santos. São Paulo: Edusp.

Yazbek, A. C. (2020).Ou a vida ou o lucro: a disjuntiva neoliberal e a gestão política da morte em tempos de pandemia. Voluntas: Revista Internacional de Filosofia. v. 11, n. 47, p. 02-08. Disponível em: https://periodicos.ufsm.br/voluntas/article/view/44004. Acesso em 26 agosto. 2021. DOI: https://doi.org/10.5902/2179378644004

Recebido em: 03/10/2021

Aprovado em: 17/10/2021 